\title{
How to Build an IT Spin-Off Company
}

\author{
Jiří Tobola \\ INVEA-TECH a.s. \\ Brno, Czech Republic \\ tobola@invea-tech.com
}

\begin{abstract}
A spin-off foundation is hot topic for many R\&D groups today. Key factors of a successful spin-off include good relationship between the company and the university, stable financing with own capital, mutual benefits for both parties and enthusiastic people.

The presentation describes success story of an academic R\&D group from its foundation, spin-off phase and five years on the market. The academic part includes participation on several EU projects, growth of development team from 5 to 50 people and EU project reviewers recommendation to a commercialization of the technology.

The company part discusses establishment of the company, technology transfer and especially our original expectations and lessons learned from the business world. Covered technologies include application acceleration in FPGA (field-programmable gate array), NetFlow monitoring and network behavior analysis.
\end{abstract}

